\title{
Latent Classes of Accounting Outsourcing Firms
}

\begin{tabular}{|r|l|}
\hline Journal: & Journal of Global Operations and Strategic Sourcing \\
\hline Manuscript ID & JGOSS-02-2021-0019.R2 \\
\hline Manuscript Type: & Research Article \\
\hline Keywords: & $\begin{array}{l}\text { Accounting outsourcing, finite mixture structural equation modeling, } \\
\text { latent class analysis, segmentation, small and medium-sized enterprises }\end{array}$ \\
\hline Data Type: & Quantitative \\
\hline
\end{tabular}

\section{SCHOLARONE ${ }^{\text {m }}$ \\ Manuscripts}

Juntunen, J., Lepistö, S. and Juntunen, M. (2022), "Latent classes of accounting outsourcing firms", Journal of Global Operations and Strategic Sourcing, Vol. 15 No. 1, pp. 115-141. https://doi.org/10.1108/JGOSS-02-2021-0019 


\title{
Latent Classes of Accounting Outsourcing Firms
}

\begin{abstract}
Purpose - Outsourcing of accounting increasingly attracts research interest, but research concerning the impact of the benefits of outsourcing on firm capabilities and performance across firms remains limited. We aim to reveal the unobservable latent classes of firms that outsource their accounting functions by testing a research model concerning the topic.

Design - We build on accounting outsourcing research and adapt a research model from the literature on business services outsourcing. We analyze the data from 261 small and medium-sized enterprises (SMEs) in Europe using finite mixture structural equation modeling (FMSEM) and additional methods.

Findings - We reveal three latent classes with different research models. Thriving outsourcers $(\mathrm{N}=103)$ have a positive attitude toward accounting outsourcing and associate competitive capabilities with mediating the relationship from outsourcing benefits to firm performance. Annoyed outsourcers $(\mathrm{N}=143)$ are dissatisfied with their accounting service provider and only associate outsourcing benefits with competitive capabilities. Convenient outsourcers $(\mathrm{N}=15)$ feel comfortable with their current accounting service provider and associate outsourcing benefits with neither capabilities nor with firm performance.
\end{abstract}

Originality - The study might be the first to categorize accounting outsourcers using FMSEM. Research implications - The study initiates the discussion about the unobservable heterogeneity among accounting outsourcer . The study introduces the use of the FMSEM method in accounting outsourcing research.

Practical implications - The study offers novel insights concerning accounting outsourcers and proposes original explanations for their outsourcing decisions that would help both the outsourcers and accounting service providers. 
Keywords Accounting outsourcing, finite mixture structural equation modeling, latent class analysis, segmentation, small and medium-sized enterprises

Paper type Research paper

\section{Introduction}

Outsourcing refers to a strategic decision to transfer an activity to be carried out by another company. Accounting researchers have predominantly built on transaction cost economics (TCE) and examined topics such as outsourcing internal audits (e.g. Anderson et al., 2000; Speklé et al., 2007; Widener and Selto, 1999), offshore outsourcing (Nicholson and Aman, 2012), and how to control outsourced accounting (Aman et al., 2012; Nicholson et al., 2006). Although outsourcing of accounting is an extremely attractive option for small and medium-sized enterprises (SMEs) due to their resource constraints such as a lack of people or knowledge to fulfil the accounting functions (e.g. Marriott and Marriott, 2000), and even though SMEs are the ones that benefit most from outsourcing professional services (Munjal et al., 2019), accounting outsourcing has mainly been explored from the perspective of large firms.

Anderson et al. (2000) suggest that capabilities - the firm's capacity to deploy resources and an ability to take advantage of and improve the productivity of its resources (Barney and Hesterly, 2012) - enhance our TCE-focused understanding of accounting outsourcing decisions. Accordingly, researchers have advanced TCE with a resource-based view (RBV) (Barney, 1991; Wernerfelt, 1984) and examined the topic among SMEs using qualitative methods (Murphy et al., 2012). Other business service outsourcing researchers (Bustinza et al., 2010) have added the dynamic capabilities view (DCV) and validated a model regarding the impact of benefits of outsourcing on SMEs' capabilities and performance, but such a model remains absent in accounting outsourcing research. 
A reason for the scarce research in the topic may be the unobserved heterogeneity of the accounting outsourcers. Unobserved heterogeneity means that heterogeneity of observations is not noticed either by theory or by the empirical analysis. Therefore, it occurs when theory exists but it does not assume heterogeneity or when the specified group variables in empirical analysis do not capture heterogeneity in the data even though theory indicates heterogeneity (Becker et al., 2013). While TCE-based research on outsourcing has been connected to the contingency framework (Van der Meer-Kooistra and Vosselman, 2000), assuming heterogeneity based on some contextual variables, it has to make a priori assumptions about these variables. Thereby it does not address unobserved heterogeneity of the accounting outsourcers, for instance, regarding their perceived influence of the benefits of outsourcing on firm capabilities or performance.

The mixture modeling techniques have been developed to identify the unobserved heterogeneity. Mixture modeling refers to a broad family of statistical methods that allow researchers to reveal unobservable groups, called latent classes, from the data (Bart et al., 2005; Muthén and Muthén, 2017). Such modeling builds on the assumption that the total sample is heterogeneous, consisting of smaller, theoretically unknown groups of respondents. Mixture modeling methods extend traditional classification methods, such as cluster analysis, with which researchers categorize respondents into theory-driven categories and various variable-centered approaches, such as regression analyses, confirmatory factor analyses (CFA), and structural equation modeling (SEM), which assume that the total sample is homogeneous. Consumer researchers (e.g., Jedidi et al., 1997; Nadeem et al., 2017) and business researchers, including logistics outsourcing researchers (Juntunen et al., 2015), have long applied the use of mixture modeling in the context of SEM, called finite mixture structural equation modeling (FMSEM). FMSEM allows researchers to uncover latent classes and estimate group-specific path coefficients in a research model for each class in the data simultaneously (Bart et al., 2005). Accounting researchers (e.g. Khurana and Raman 2006; Bowen et al., 2008) have applied the use of mixture 
modeling in the context of regression analyses (called latent class mixture regression analysis), but the use of the FMSEM method seems to be absent in the accounting outsourcing research.

The purpose of this paper is to uncover the latent classes of accounting outsourcing firms along with their respective model for the impact of benefits of outsourcing on firm capabilities and performance. We build on accounting outsourcing research and adapt a research model from the literature on services outsourcing. Our empirical data is collected from a survey of 261 companies in Finland that have outsourced accounting transactions. The companies represent various industries and the majority of the companies $(98.5 \%)$ are SMEs. We estimate the latent classes and their group-specific research models using FMSEM and test statistically significant differences between the classes by using Kruskal-Wallis test and its post hoc pairwise comparisons test. The study extends the discussion regarding heterogeneity from the outsourced accounting transactions (Carey et al., 2006; Van der Meer-Kooistra and Vosselman, 2000) to the unobserved heterogeneity of the outsourcers.

The article is organized as follows. First, the theoretical background is presented, followed by the conceptual model and hypotheses. Next, the methodological issues discussed. The empirical results are then presented and contributions discussed. The paper ends with the discussion on limitations and further research opportunities related to the study.

\section{Accounting and outsourcing}

\section{Outsourcing in accounting research}

According to Venkatesan (1992), the premise for outsourcing is that a firm is better off when it focuses on activities in which it possesses a sustainable competitive advantage, and externalizes those in which competing companies have a specific competitive advantage. Accounting functions are important in every business, as bookkeeping is obligatory and management can use accounting information for decision-making. Accounting service providers have accounting tasks as their core 
competence and have a competitive advantage in terms of costs, quality and technical competence (Carey et al., 2006; Michael, 2008). Accordingly, if the company is lacking in terms of people or knowledge to fulfil the accounting functions, the outsourcing option becomes attractive (Dibbern and Heinzl, 2002). While accounting functions are also connected with accounting information systems, the resources for IT are also relevant for decision to outsource accounting (see Hanafizadeh and Zareravasan, 2020). This is especially relevant for SMEs, since resource constraints are much more significant for them than they are for large firms (Marriott and Marriott, 2000). Especially micro-enterprises (companies with fewer than 10 employees) hardly have any choice between outsourcing and internalizing (Everaert et al., 2010), which means that their choice is really not about Coase's (1937) traditional "make or buy" decision, but about how and what accounting tasks to outsource.

There are three main streams of literature in accounting regarding outsourcing related to accounting outsourcing, firm performance and capabilities. Research on accounting outsourcing is predominantly based on TCE. Research has mapped out characteristics of transactions and their related costs in order to find out what kind of transactions are suitable for outsourcing in order to gain cost benefits (e.g., Vosselman, 2002). Research conceptualizes these benefits based on cost savings and quality improvements (e.g. Smith et al., 2005), and models both the costs and the benefits of the decisions through transaction costs determined by the asset specificity, environmental and behavioral uncertainty, as well as the frequency of transactions (Widener and Selto, 1999). While TCE-literature has acknowledged that cooperation with a service provider enables development of the relationship and more transactions to be outsourced (Speklé, 2001), and recent research has shown how the service provider may contribute the development of the relationship by its legitimating efforts (Lepistö et al., 2020), earlier research has provided limited understanding of the influence of outsourcing accounting functions on firm performance. 
Researchers have recently advanced the TCE perspective with the RBV and the DCV. The RBV is premised on strategic resources being heterogeneously distributed across firms (Barney, 1991). The distribution is seen as being rather stable and the unique resources and capabilities that an organization possesses as the source of competitive advantage. Human capital (the capabilities of individual employees) and organizational capital (included in the organizational structures) can be such unique resources. Physical resources are usually imitable and not alone sufficient for a sustainable competitive advantage, but their combination may provide uniqueness and a competitive advantage (Barney, 1991; Wernerfelt, 1984). The DCV questions the stability of the RBV view and states that the source of competitive advantage is the competitive capabilities, meaning how the resources are continuously integrated, built and reconfigured to build this competitive advantage (Teece et al., 1997).

The two other streams of accounting research on outsourcing have benefitted from these views. First, the RBV has been used as an explanation to why firms outsource some of their noncore functions to focus on their more important capabilities. Eldenburg et al. (2019) claim that outsourcing non-core functions reduces uncertainties that arise in dealing with regulators of offshore outsourcing, so that the firm can focus on its more important capabilities and, thus, manufacturing outsourcing is more long-lived. Carey et al. (2006) show that when a firm believes that an internal audit service provider has better technical competence than the firm itself, in addition to cost benefits, the firm is prone to outsource its internal audit. Research has combined the TCE cost view with RBV stating that asset specificity refers to the unique resources of RBV. This means that outsourcing may not benefit the firm, if unique knowledge of operational activities is needed to conduct the activities prone to being outsourced (Widener and Selto, 1999). Additionally, researchers have recognized that core competencies may be affected by how the outsourcing relationship is controlled (Mouritsen et al., 2001). Accordingly, the literature acknowledges that 
outsourcing a non-core function may affect firm performance in other ways than by just reducing costs.

The second stream delves deeper into the understanding of how resources and capabilities are combined for advancing firm performance by exploring management control systems (MCSs). The use of certain MCSs may be organizational capital and support capabilities and the combinations of resources, which support strategic choices affecting firm performance (Henri, 2006). Whereas Henri (2006) states that capabilities are about linking resources together to deploy them and that the use of MCS can support this process to affect firm performance, Widener (2006) explores the mediating effect of performance measures between strategic resources and firm performance, without mentioning capabilities. Grafton et al. (2010) explore how the use of decision-facilitating and decision-influencing performance measures impacts capabilities and subsequently performance, and Mitter and Hiebl (2017) even state that management accounting may be a key capability in some phases and situations of international entrepreneurship, as it helps in the combining of resources.

When we acknowledge that accounting outsourcing is a question of firm governance, as management control systems are, we could state that outsourcing a non-core function in an SME, such as accounting, will bring benefits that help deploying (unique) resources for generating capabilities and affect firm performance positively. Despite the contributions above, the existing research lacks a model that explains how the influence of outsourcing benefits on competitive capabilities and firm performance differ among firms that outsource accounting. The following section introduces such a model.

\section{Financial services sector in Finland}

Financial services sector has been growing in Finland, which means that more and more outsourcing of those services is taking place. There are over 4,200 accounting service provider 
firms with over 11,700 employees in Finland, whereas the toltal sales of the firms is about 970

Million Euros (Statistics Finland, 2017). The members of the Association of Finnish Accountancy

Firms do accounting for over 150,000 firms, which are mostly small and medium-sized. An

accounting service provider firm has 9,1 employees of average and an employee has on average 27

customers (Taloushallintoliitto ry, 2017). Polarisation goes on in the industry as few large

nationwide chains are actively expanding by buing small and medium-sized service providers and also acquiring companies that specialize in software and invoicing, which support their services (Ministry of Eonomic Affairs and Employment, 2019). It has indeed been found that users of cloudbased accounting information systems outsource a larger variety of accounting processes compared to users of traditional systems (Asatiani et al., 2019). Digitalization is also changing the industy making future accounting professional service professionals and business consultants who are adept at utilizing electronic services (Ministry of Eonomic Affairs and Employment, 2019).

\section{Conceptual model and hypotheses development}

\section{Conceptual model}

We adopt our conceptual model (Figure 1) from Bustinza et al. (2010) who studied the matter in the service sector. The model consists of three main concepts - accounting outsourcing benefits, competitive capabilities and firm performance - and hypothesized relationships (H1-H3) between these concepts. Dashed arrows from the variable "Differences among latent classes" to the hypothesized relationships between the concepts indicate the assumed unobserved heterogeneity between the firms that outsource their accounting functions in terms of the strength of the relationships. We present the hypotheses next, followed by justifications for the assumption of heterogeneity among accounting outsourcing firms.

- Insert Figure 1 about here - 
The cost-based explanation of outsourcing benefits is rather limited and other business literature has provided a more comprehensive discussion on these benefits (see, Kremic et al., 2006). These benefits are often based on the perspective that when the right outsourcing decisions are made, the resulting benefits serve to strengthen the company's internal resources (Nordin, 2008). One main benefit of outsourcing is the possibility to invest capital in core activities, or core competencies, which should be difficult for competitors to imitate (Prahalad and Hamel, 1990). Bustinza et al. (2010) further categorize the benefits to organizational benefit indicators such as an improvement in management processes and reducement in organizational risks, and business benefit indicators, including, for instance, improvements in customer satisfaction and strategic positioning.

Accounting research has explored how competitive capabilities, competitive advantage and organizational capabilities are related to management control systems (MCSs) and, subsequently, firm performance (Grafton et al., 2010; Henri, 2006). According to Grant (1991), capabilities are defined as a firm's strengths based on a combination of resources working together, which makes it plausible that they are affected by how MCSs and accounting information are used (Grafton et al., 2010; Henri, 2006). As outsourcing allows the company to concentrate on those business activities that create greater competitive advantages for it (Pinjala et al., 2006), the benefits of accounting outsourcing should have an impact on the competitive capabilities of the firm. Bustinza et al. (2010) revealed that the greater the benefits of the outsourcing decisions, the greater the positive impact of these decisions on the firm's competitive capabilities. Based on the above discussion, the first hypothesis is:

H1: Benefits of outsourcing accounting have a positive impact on a firm's competitive capabilities.

Since the effect of accounting outsourcing on competitive capabilities may be twofold, we base our research on findings that using accounting information may have an impact on firms' competitive 
capabilities and, thus, firm performance. Not only accounting outsourcing researchers (Grafton et al., 2010) but also outsourcing researchers in many other business fields including HR (AbdulHalim et al., 2009) and service firms (Bustinza et al., 2010) have confirmed that competitive capabilities influence firm performance. The second hypothesis is thus:

H2: Competitive capabilities have a positive impact on a firm's performance.

As the previous hypotheses indicate, competitive capabilities have been found to be a mediator between outsourcing benefits and firm's performance in earlier literature (Bustinza et al., 2010). However, if we assume that a firm relies on an accounting service provider that has a competitive cost advantage in producing accounting information, the cost of accounting services would reduce (Michael, 2008). This is in accordance with the TCE literature modelling outsourcing decisions based on lower transaction costs. This means that, there may also be a direct link between the benefits of outsourcing and firm's performance if outsourcing directly diminish the costs of the outsourcer. Although researchers (e.g. Bustinza et al., 2010) have been unable to verify the relationship between outsourcing benefits and firm's performance, it is widely confirmed that outsourcing in general has a positive influence on firm performance (e.g. Gilley et al., 2004; Golhar and Deshpande, 2009). Therefore, we assume that outsourcing accounting would also have a direct link to firm performance and the third hypothesis is:

H3: Benefits of accounting outsourcing have a positive impact on a firm's performance.

Research recognizes both the observable and unobservable heterogeneity across outsourcing firms. Regarding observable heterogeneity, Munjal et al. (2019) revealed that it is small firms that typically benefit most from outsourcing professional services and technology, especially if they lack resources or are fast-growing. Others identified differences in outsourcing strategies: a long-term strategy is based on deep co-operation with a selected service provider and it is designed to ensure 
the prosperity of the enterprise; while a short-term strategy is characterized by competitive relationships with multiple service providers and it considers outsourcing as a manner in which to reduce employment, the cost of salaries, or to eliminate the conditions and rights acquired by employees through collective negotiations (e.g. Andone and Pavaloaia, 2010; Juntunen, 2010; Juntunen et al., 2010).

Regarding unobservable heterogeneity, researchers have revealed two latent classes of logistics outsourcing firms in terms of cost performance, service performance and loyalty (Juntunen et al., 2015). Other business researchers have revealed three latent classes of internationalizing SMEs with different resource and capability portfolios (Haapanen et al., 2016). This indicates that the unobservable heterogeneity may exist between accounting outsourcing firms, specifically regarding capabilities and among SMEs. We will next explain our methodological choices in order to reveal such heterogeneity in our data.

\section{Method}

Data

The data was collected in Finland in 2017. The data collection contained two samples, each of which had two waves. First, a link to the questionnaire was emailed to 2000 randomly chosen companies in the Asiakastieto.com registry, which contains the contact information of approximately 37000 companies in all industries (approximately $13 \%$ of all companies) in Finland. Firms that were working in the industry of accounting services were excluded. A remainder was sent a week later, in order to increase the response rate and to reduce a nonresponse bias (Lambert and Harrington, 1990). The waves yielded 34 and 21 answers, respectively, resulting in the total of 55 answers and the response rate was $2.75 \%$. Due to the low number of responses, the same link was emailed to 10000 randomly chosen respondents in the same registry, excluding the firms that had received the link in the first stage. A reminder was sent two weeks later. The waves 
yielded in 109 and 105 responses, respectively, resulting in a total of 214 responses with a response rate of $2.14 \%$. The total number of responses was 269 yielding a response rate of $2.24 \%$. Although the response rate is low, the total number of responses is acceptable for the purposes of statistical research conducted using the methods of the current study. As eight questionnaires were inadequately filled, they were excluded, resulting in the effective sample size of 261.

As the data proved to be non-normally distributed, nonresponse bias (Armstrong and Overton, 1977; Lambert and Harrington, 1990) between the samples was tested by using a Kruskal-Wallis test. A statistically significant difference $(p<0.05)$ was revealed in four out of 43 model variables between the two samples. No significant non-response bias $(\mathrm{p}<0.10)$ in the study exists, which allows conducting the further analysis of the combined sample, and the results of these analyses can be generalized to the whole population in this regard (Lambert and Harrington, 1990). Samples were combined and used as a single sample in the further analyses.

Of the sample, 224 (85.8\%) companies were micro-sized and had less than 10 employees; 26 (10\%) companies had 10-49 employees; 6 (2.3\%) companies had 50-249 employees; and only 4 (1.5\%) companies had 250 employees or more. $1(0.3 \%)$ respondent did not answer the question. The data is heavily skewed toward micro-sized firms, which reflects the fact that these companies seldom have another choice than outsourcing (Everaert et al., 2010). However, the distribution of the companies in the sample approximately follows the distribution of the whole population of the Finnish companies (Statistics Finland, 2017).

\section{Measurement of variables}

We adapt the measurement model from the literature on business services outsourcing. In line with the conceptual model, the measurement model consists of three main factors: benefits of outsourcing factor, influence on competitive capabilities factor, and firm performance factor. Each of them is a second-order factor consisting of two, two and five sub-factors, respectively. 
Benefits of the outsourcing factor consist of the business benefits factor and organizational benefits factor. Measures for the factors are adapted from Bustinza et al. (2010) and the factors contain six and five items, respectively (see, Appendix 1). Items were measured by using a 7-point scale $(1=$ not benefitting at all ...7=extremely benefitting).

The influence on the competitive capabilities factor consists of two sub-factors: internal impact factor and external impact factor. Measures for these factors are adapted from Bustinza et al. (2010), and the factors contain five and six items, respectively. Items were measured by using a 7point scale ( $1=$ extremely unimportant $\ldots .7=$ extremely important $)$.

Firm performance factor consists of five sub-factors: internal business performance factor, external business performance factor, organizational performance factor, innovation performance factor, and stakeholder performance factor. Items for each factor were adapted from the existing services outsourcing literature, and the factors contain two to six items (see, Appendix 1), thereby extending accounting research which often focuses on accounting measures and other financial factors rather than such multi-item construct to measure firm performance. Items were measured by using a 7 -point scale ( $1=$ lowest in our industry...7=highest in our industry).

As the outsourcing strategy might distinguish the outsourcing firms, we adapted five items concerning outsourcing strategies (Juntunen, 2010) and customer loyalty (Vogel et al., 2008), which can be seen as a long-term outsourcing strategy, as control variables. Items were measured by using a 7-point Likert scale (1=totally disagree ...7=totally agree).

Because the language of the sample was Finnish, the questions were translated into Finnish and then back into English in order to ensure consistency. The questionnaire was pre-tested by representatives of two different companies and revised accordingly.

\section{Analyses and findings}


Structural equation modeling (SEM) analyses

The analysis started with structural equation modelling (SEM), in order to test whether the theoretical model was statistically compatible with the data. SEM allows one to validate both the measurement and structural model simultaneously. Estimations were made by using the MPlus software using the robust maximum likelihood (MLR) estimation method, as it is robust to nonnormality (Muthén and Muthén, 2017).

The structural model (Appendix 2) provides both acceptable and unacceptable fit indices. The Standardised Root Mean Residual (SRMR) value of 0.076 is between 0 and 0.08 , which is the acceptable range for the index (Hu and Bentler, 1999). The Root Mean Square Error of Approximation (RMSEA) value of 0.092 is over 0.08 , which represents the reasonable error of the approximation of the model (Browne and Cudeck, 1993). It is also within the range of 0.08 to 0.10 , which indicates a mediocre fit (MacCallum et al., 1996). The Comparative Fit Index (CFI) value of 0.853 and Tucker-Lewis Index (TLI) value of 0.843 are less than the required cut-off criteria 0.90 (Jaccard and Wan, 1995), as well as the chi-square value is 2444 (d.f. 767), which gives a p-value of 0.000 . The hypothesized relationship H1 is statistically significant (standardized coefficient 0.721; p-value 0.000 ), whilst both $\mathrm{H} 2$ and $\mathrm{H} 3$ are statistifically non-significant (standardized coefficients 0.120 and 0.098 ; and p-values 0.260 and 0.356 , respectively). Due to unacceptable fit indices and the existence of non-significant relationships, the structural model cannot be accepted.

The constructs of the model, however, provide statistically acceptable fit indices. Construct reliabilities (CR), average variance extracted (AVE) and Cronbach's alpha (ALPHA) values are all at an acceptable level for all second-order constructs and their first-order sub-constructs. All factor loadings are statistically significant, which depicts that the construct validity and communality are acceptable (Hair et al., 2010: 708). However, two factor loadings are low (See items porg1 and porg2 in appendix 1) but statistically significant and hence fulfill only a weak convergent validity 
(Steenkamp and van Trijp, 1991). Items are included in measurement model to improve measurement strength of the model.

We next tested a rival structural model that contained $\mathrm{H} 1$ and $\mathrm{H} 2$ only, because some researchers (e.g. Bustinza et al., 2010) have been unable to confirm H3. This model also provides unacceptable fit indices (chi-square value 2024; d.f. 691; p-value 0,000; SRMR 0,069; RMSEA 0,086; CFI 0,880; TLI 0,871), and therefore, although both of the relationships offer statistically significant values (standardized coefficients 0.723 and 0.000 ; p-values and 0.189 and 0.006 , respectively), the model cannot be accepted.

In conclusion, the measurement structures of the constructs are valid, but the structural models provided unacceptable fit indices and non-significant relationships between the constructs. This raises the question of whether the data is heterogeneous concerning the hypothesized relationships between the constructs. We continued with FMSEM analyses.

\section{Finite mixture structural equation modeling (FMSEM) analysis}

In order to reveal the possible unobservable heterogeneity of the data, we continued with FMSEM analyses. Also these analyses were conducted with the MPlus software and using the MLR method.

We estimated a research model that comprises of the three confirmed second-order factors above for each class, but let the slope of the linear regressions of the latent variables vary between the latent classes, that is, let the hypothesized relationships across the latent classes vary. We extracted the number of the latent classes; the members of each class; and the respective structural model for each class concurrently. We estimated the solution first by using two latent classes, then using three classes and so on, until the model-fit information suggested that the previous solution was better than the current solution. In order to find the best solution for each number of classes, we changed the number of starting values and iterations (Muthén and Muthén, 2017). 
We evaluated the solutions for the different number of latent classes with the help of the multiple fit indices the MPlus software reports. The lower absolute value of the Log-likelihood value in solutions with more classes indicates that the estimation is conducted properly (Table 1). Bayesian information criteria (BIC) value, which is the most reliable fit index with small sample sizes $(\mathrm{N}<500)$ (Tolvanen, 2007; Juntunen et al., 2015), suggests the solution of three latent classes. This is supported by the parametric bootstrapped likelihood ratio (PBLR) value, which is always reliable when it can be estimated. The highest entropy value suggests the solution of four classes. Although the lowest values of the Akaike's information criteria (AIC) value, the Adjusted Bayesian information criteria (ABIC) value, the Vuong-Lo-Mendell-Rubin likelihood ratio test (VLMRLRT) value and the Lo-Mendell-Rubin adjusted likelihood ratio test (LMRALRT) value also indicate that the solution of four latent class would be the best option, these indices are typically valid for large sample sizes $(\mathrm{N}>500)$ and can be ignored. In addition, in the solution of four latent classes, the smallest class has only 9 members $(3.4 \%)$, which is less than the required minimum class size of 5 $\%$ (Muthén and Muthén, 2017). On the basis of this evaluation, we concluded that the solution of three latent classes is the best solution and continued with it.

\section{- Insert Table 1 about here -}

The solution of three latent classes suggests that the first latent class (LC1) has 103 members (39.5 $\%$ of the population), the second latent class (LC2) has 143 members (54.8\%), and the third latent class (LC3) has 15 members (5.7\%). We gave a name for each class - Thriving outsourcers, Annoyed outsourcers, and Convenient outsourcers, respectively, during our further analyses, as we will explain below. Based on the average posteriori probabilities (Table 2), the probability of the members to belong in the suggested classes is very high. 
Standardized estimates and p-values show that the structural model for each class differs remarkably from the model of other classes (Table 3). For Thriving outsourcers, the model shows that the hypothesized relationships $\mathrm{H} 1$ and $\mathrm{H} 2$ are statistically significant but $\mathrm{H} 3$ is statistically nonsignificant. This means that for this class, $\mathrm{H} 1$ and $\mathrm{H} 2$ are supported whilst $\mathrm{H} 3$ is not supported. For Annoyed outsourcers, the hypothesized relationship $\mathrm{H} 1$ is statistically significant but $\mathrm{H} 2$ and $\mathrm{H} 3$ are statistically non-significant. For this class, H1 is supported whilst H2 and H3 are not supported. For Convenient outsourcers, all the hypothesized relationships $\mathrm{H} 1, \mathrm{H} 2$ and $\mathrm{H} 3$ are statistically nonsignificant. In this class, none of the hypotheses $\mathrm{H} 1-\mathrm{H} 3$ is supported.

- Insert Table 3 about here -

At this phase, we checked the models for the solutions of two latent classes and four latent classes in order to confirm that the solution for three latent classes is the one which makes theoretically most sense, also in terms of the models for the classes. In the solution of two latent classes, the model structures were in line with those of Thriving outsourcers and Annoyed outsourcers above, and the model for $92.7 \%$ of the respondents was similar than in the solution of three latent classes. In the solution of three latent classes, all except one respondent, that is $93.3 \%$ of Convenient outsourcers was categorized into a class of Thriving outsourcers in the solution of two latent classes. This confirms that the models for Thriving outsourcers and Annoyed outsourcers exist across solutions, yet the solution for three latent classes provides more explanatory power for the phenomenon at hand. The solution for four latent classes produced theoretically unacceptable estimates, that is, absolute values outside the range of $0-1$, thereby confirming that continuing with the solution of four latent classes is out of the question. 
Then, we wanted to find explanations as to why the structural model for each class is different and what other explanations there are for the existence of the classes. The following section presents the results of this analysis.

\begin{abstract}
Kruskal-Wallis test's pairwise comparisons tests
In order to test whether there are significant statistical differences between the classes in terms of variables, we conducted a Kruskal-Wallis H-test by using the IBM $^{\circledR}$ SPSS $^{\circledR}$ Statistics version 24 software package. The test shows no statistically significant difference in the mean ranks of the classes in terms of demographic variables, that is, the firm size $(H=0.750, p=0.687)$, firm age $(\mathrm{H}=1.415, \mathrm{p}=0.493)$, or industry $(\mathrm{H}=0.396, \mathrm{p}=0.820)$. As the test shows statistically significant differences in the mean ranks of the classes in 37 out of 46 variables $(80.4 \%)$, we conducted post hoc tests to test pairwise comparisons in order to reveal statistically significant differences between the classes (Appendix 3; Figure 2). We introduce these results construct-wise and variable-wise next, along with explaining how the findings helped us to name the classes.
\end{abstract}

- Insert Figure 2 about here -

Benefits of outsourcing and the impact on competitive capabilities. The pairwise comparisons test provides statistically significant differences in the mean ranks of Thriving outsourcers and Annoyed outsourcers in all variables of the following factors: business benefits, organizational benefits, internal impact, and external impact (see, Appendix 3). The median response by Thriving outsourcers to the variables of these factors is most often higher than neutral ( $>4)$ or neutral (4), indicating a general positive attitude of the class members towards outsourcing benefits and its impact on competitive capabilities. This, along with other justifications as we explain below, encourages us to call the class Thriving outsourcers. The median response by Annoyed outsourcers 
to the variables of these factors is typically lower than neutral $(<4)$ or neutral $(4)$, which indicates their general negative attitude towards outsourcing benefits and its impact on competitive capabilities. We call the class Annoyed outsourcers and offer more justifications for the name below.

Median responses by Convenient outsourcers to the variables of the business benefits, organizational benefits, and external impact factors are typically between the medians of the other two classes or the same, varying from higher than neutral $(>4)$ to neutral (4) to lower than neutral $(<4)$. In other words, Convenient outsourcers consider some aspects related to accounting outsourcing benefitting and important, while others as non-benefitting and non-important. We name the class Convenient outsourcers, and explain this more below. In terms of business benefits and organizational benefits, the pairwise comparisons test provides statistically significant differences in the mean ranks of Convenient outsourcers and Thriving outsourcers in two variables (bb3, $\mathrm{p}=0.037 ;$ bo $4, \mathrm{p}=0.026$ ). The mean ranks of Convenient outsourcers for these variables are significantly lower than those by Thriving outsourcers (see, Figure 2), reflecting that while Thriving outsourcers perceive that accounting outsourcing benefits them by increasing their customer satisfaction and innovation trends, Convenient outsourcers consider the opposite. Additionally, the test provides statistically significant differences in the mean ranks of Convenient outsourcers and Annoyed outsourcers in the terms of variable bo2 $(\mathrm{p}=0.021)$, meaning that Convenient outsourcers perceive that their access to latest technologies due to accounting outsourcing is significantly more benefitting for them than Annoyed outsourcers perceive it to be for them. In terms of internal and external impact factors, the test shows statistically significant differences in the mean ranks of all variables of Convenient outsourcers and Annoyed outsourcers, the mean ranks of Convenient outsourcers being even higher than those of Thriving outsourcers. This means that Convenient outsourcers consider the internal and external impacts of accounting outsourcing to be significantly more important than Annoyed outsourcers. 
Firm performance. No statistically significant differences were found in the mean ranks of classes in variables of the internal business performance factor, meaning that all classes are similar to what comes to their internal business performance. Related to the external business performance factor and its variable pext2, the statistically significant difference was found in the mean ranks of Convenient outsourcers and Thriving outsourcers $(\mathrm{p}=0.007)$, as well as of Convenient outsourcers and Annoyed outsourcers $(\mathrm{p}=0.013)$, meaning that both Thriving outsourcers and Annoyed outsourcers consider the importance of growth in sales in main services and markets as a result of accounting outsourcing being significantly more important than Convenient outsourcers do. In terms of the organizational performance factor and its three variables (porg4, porg5, porg6), the test shows statistically significant differences in the mean ranks of Thriving outsourcers and Annoyed outsourcers $(\mathrm{p}=0.000, \mathrm{p}=0.001$ and $\mathrm{p}=0.003$, respectively), as well as of Convenient outsourcers and Thriving outsourcers $(\mathrm{p}=0.000, \mathrm{p}=0.006$ and $\mathrm{p}=0.030$, respectively). This means that Convenient outsourcers consider that their organizational performance in terms of the general level of customer satisfaction, the degree of loyalty of customers, and customer relations in general are better than in the firms in their industry on average. The finding differs significantly from Thriving outsourcers, who hold opposite perceptions.

In terms of innovation performance and its two variables (pinn1, pinn2), the test shows statistically significant differences in the mean ranks of Convenient outsourcers and Thriving outsourcers ( $\mathrm{p}=0.001, \mathrm{p}=0.000$, respectively) and of Annoyed outsourcers and Convenient outsourcers $(\mathrm{p}=0.005$ and $\mathrm{p}=0.003$, respectively), reflecting that Convenient outsourcers consider their innovation performance in terms of $R \& D$ outlays and the amount of process innovations to be much weaker than the firms in their industry on average. The finding differs significantly from the perceptions of other classes, who consider their performance to be similar to other firms in their industry. Related to stakeholder performance and its variable pstake1, the test shows statistically significant difference in the mean ranks of Convenient outsourcers and Thriving outsourcers 
$(\mathrm{p}=0.008)$, as well as of Annoyed outsourcers and Convenient outsourcers $(\mathrm{p}=0.004)$. This indicates that Convenient outsourcers consider their employment growth to be weaker than the firms in their industry on average do, and significantly weaker than the two other classes do. Additionally, statistically significant differences were revealed in the mean ranks of Thriving outsourcers and Annoyed outsourcers concerning two variables (pstake2, $\mathrm{p}=0.002$; pstake $3, \mathrm{p}=0.009$ ), indicating that Thriving outsourcers consider their employee morale and level of satisfaction with supplier better than the firms in their industry on average and significantly better than Annoyed outsourcers do.

Control variables. The test shows statistically significant differences in the mean ranks of Thriving outsourcers and Annoyed outsourcers in terms of their current amount of outsourcing (outnow $1 ; \mathrm{p}=0.000$ ), but no statistically significant differences in the mean ranks of the classes was revealed in terms of how much of the outsourced function the firm could actually conduct by themselves. Related to future outsourcing plans and strategies, the test shows statistically significant differences in the mean ranks of Thriving outsourcers and Annoyed outsourcers in all variables. Again, medians by Thriving outsourcers are considerable higher than those by Annoyed outsourcers, reflecting their positive and negative attitude, respectively, towards outsourcing in the future. Additionally, Annoyed outsourcers have the lowest intentions to outsource more, to strengthen the cooperation with, or recommend their current service providers. The test also shows statistically significant differences in the mean ranks of Convenient outsourcers and Thriving outsourcers concerning two variables (outplan $2 \mathrm{p}=0.006$; outplan $4 \mathrm{p}=0.003$ ), meaning that Thriving outsourcers aim to outsource more to a new service provider and increase competition among their service providers significantly more than Convenient outsourcers, who have the lowest intentions for these, but the highest intentions to strengthen the cooperation with their current providers. We discuss these three groups of accounting outsourcers and their respective models next. 


\section{Discussion}

We revealed three latent classes of accounting outsourcers. Thriving outsourcers $(\mathrm{N}=103)$ is the most satisfied class with accounting outsourcing in general and with their current accounting services provider particularly. As they perceive, outsourcing benefits them through increases in customer satisfaction and innovation trends that also improve their internal and external competitive capabilities. These outsourcers have probably analyzed which transactions are the most prominent to be outsourced and that a close cooperation with a service provider enables a larger variety of transactions to be successfully outsourced (Speklé, 2001) and building a strong trustworthy relationship (Hanafizadeh and Ravasan, 2017). A structural model for Thriving outsourcers is in line with the research on services outsourcing (Bustinza et al., 2010), which indicates that these firms have acknowledged that outsourcing allows them to focus on developing and deploying their more important capabilities, which again affects firm performance, also in more versatile ways than only by cutting costs (Henri, 2006). As accounting activities are connected with IT, this finding is also in line with findings in IT outsourcing research indicating that intangible benefits for decision to outsource may be more important than the tangible ones (Hanafizadeh and Ravasan, 2017). Thriving outsourcers plan to increase their outsourcing in the future and, despite their satisfaction, may also use other service providers that they currently have. This is in line with research which has recognized that long-term strategic approaches in outsourcing are characterized by deep cooperation with a selected service provider (Andone and Pavaloaia, 2010; Juntunen, 2010), but also proneness to use outsourcing more widely to improve competitive capabilities and firm performance. It is also in line with Carey et al. (2006) in that the firms here made the decision to outsource based on the perceived value of the service provider, which is based on the big picture of the benefits that the service provider offers, not only accounting capabilities, quality and efficiency, but also access to IT solutions. Therefore, the decision to outsource was not probably driven by topdown strategy to outsource or out of pure necessity. This means that Thriving outsourcers have 
probably analyzed carefully the different reasons related to technological attributes such as benefits, risks and complexity in additions to environmental and user attributes, when making their outsourcing decisions and thus getting benefits out ouf the relationship. Moreover, they probably have many organizational attributes positive towards outsourcing, such as skills and competencies, trust towards to service provider, positive attitude and management support (see Hanafizadeh and Zareravasan, 2020).

Annoyed outsourcers $(\mathrm{N}=143)$ is the most dissatisfied class with accounting outsourcing in general and with their current accounting services provider particularly. This is reflected by their marginal intentions to outsource more to, strengthen the cooperation with, or recommend their current service providers. The model for the class shows that the class realizes that outsourcing enables developing capabilities, but it has not been able to develop those capabilities and does not consider outsourcing to be a way in which to enhance firm performance, which is in stark contrast with Thriving outsourcers. The decision of outsource has probably been done out of necessity without further analysis resulting in getting neither the service they desire nor any perceived benefits, which causes negative attitudes questioning decisions to outsource in the future (Hanafizadeh and Zareravasan, 2020). The existence of such outsourcers questions the models that are based on some kind of rational decision-making, whether based on costs or resources/capabilities. However, the inability to develop capabilities with the help of accounting outsourcing reflects similar findings as Mitter and Hiebl (2017) who find that accounting may be important in developing capabilities, which again may be hindered by outsourcing it. Therefore, accounting outsourcing is not always the most efficient way for firm governance, but keeping the capabilities inside the firm could provide more benefits.

Convenient outsourcers $(\mathrm{N}=15)$ are neither extremely satisfied nor extremely dissatisfied with accounting outsourcing or with their current accounting services provider. They probably consider relationships to be important, as they have the highest intentions to strengthen the cooperation with 
their current providers. Thereby this class also has characteristics of a long-term strategic approach in outsourcing (Andone and Pavaloaia, 2010; Juntunen, 2010), yet probably they have just not given it much thought. The model for the class shows that while the class members perceive that outsourcing benefits, in particular, access to the latest technologies, they associate these benefits neither with capabilities nor with firm performance. They have probably outsourced their accounting out of convenience without trying to reach other benefits than to skip doing certain transactions internally, but Their decision may also be related to IT issues, as they seem to be especially in the benefits from technological attributes (Hanafizadeh and Ravasan, 2017). This group does not fit to the ideas where the decision to outsource is done based on a thorough analysis of transaction costs or effects on competitive capabilities.

None of the three classes associate the benefits of accounting outsourcing directly to firm performance. The finding contradicts research suggesting that outsourcing in general has a positive influence on firm performance (e.g. Gilley et al., 2004; Golhar and Deshpande, 2009), but it is similar to that of Bustinza et al. (2010) and in line with RBV in that the cost benefits may not directly translate to a firm performance, as they do not constitute an unique capability (Barney, 1991; Henri, 2006), yet the cost benefits may free resources for developing and deploying more unique resources and capabilities. Overall, our findings confirm, illustrate and explain the heterogeneous nature of accounting outsourcers and show the multitude of factors in play in accounting outsourcing decisions. Table 4 summarizes the findings of the research related to the three streams of accounting literature introduced in theory section. Our findings are in line with the earlier research with the exception of TCE-based literature. However, it is worthwhile to note that the earlier accounting research is predominantly based on large firms outsourcing their accounting or other functions. Therefore, our findings specifically show how heterogeneous the accounting outsourcing situations of small and medium-sized firms may be. Transactions costs and tangible benefits do not seem to be the most important reason behind outsourcing, but more intangible 
reasons, such as focusing the limited resources to more important capabilities plays a bigger role (see Hanafizadeh and Ravasan, 2017). However, our results do not reveal all the reasons behind accounting outsourcing as outsources may be quite content with the situation without explicit link between outsourcing and other capabilities.

- Insert Table 4 about here -

\section{Conclusions}

\section{Research implications}

Our study offers varios implications to the accounting outsourcing literature. First, we apply a novel theoretical approach in our research. Accounting outsourcing has predominantly been based on TCE (e.g. Aman et al., 2012; Nicholson and Aman, 2012), and although researchers have advanced it with RBV (e.g. Henri, 2006; Murphy et al., 2012), utilizing DCV has remained scarce. Other business service outsourcing researchers (Bustinza et al., 2010) have added DCV and validated a model regarding the impact of benefits of outsourcing on firm capabilities and performance, but such a model has remained absent in accounting research. Our study closes these gaps.

Second, we introduce three latent classes of accounting outsourcers and their research models concerning the impact of the benefits of outsourcing on firm capabilities and performance. Our data was inadequate to fit the research model we adapted from the business services outsourcing research (Bustinza et al., 2010). Instead, we revealed that the model for each latent class is different, reflecting their satisfaction with and their strategic choices related to accounting outsourcing. This confirms that one research model might be insufficient to express the unobserved heterogeneity across firms that outsource accounting, thereby explaining why reseach on the topic has remained limited. Our study also extends the FMSEM research regarding firm resources and capabilities (Haapanen et al., 2016) by adding the concept of firm performance. 
Third, we confirmed the measurement structures for the concepts benefits of outsourcing, the impact on competitive capabilities, and firm performance. We verified that the measures developed by Bustinza et al. (2010) for the constructs benefits of outsourcing and the impact on competitive capabilities are valid in the context of accounting outsourcing as well. Our study widens the view of the benefits from accounting outsourcing, which has this far been mainly focused on transaction costs (e.g., Carey et al., 2006; Widener and Selto, 1999), while also limitedly acknowledging that core competencies affect the decision to outsource. We expand the concept firm performance by validating a measurement model that is a second-order construct consisting of five sub-factors. Accounting researchers usually measure firm performance from financial perspective and accounting measures, and our study thus widens the view to multi-item organizational performance. Researchers in other business fields have measured firm performance by using one (e.g. Ellinger et al., 2000), two (e.g. Golhar and Deshpande, 2009), three (Bustinza et al., 2010) or four (Gilley et al., 2004) of these factors, yet we found no research that would have used this extensive measurement model for firm performance. With these contributions, our study creates a sound platform for further research on outsourcing, both in accounting and other business fields.

Methodologically, although latent class research using the FMSEM method has been widely used in consumer research (Bart et al., 2005; Jedidi et al., 1997; Nadeem et al., 2017) and in business research (Haapanen et al., 2016), including logistics outsourcing research (Juntunen et al., 2015), the approach has been non-existent in the field of accounting, which has focused on the exante analysis of transaction costs and contingency factors (e.g. Carey et al., 2006; Widener and Selto, 1999) or used latent class mixture regression analysis only (e.g. Khurana and Raman 2006; Bowen et al., 2008).

Managerial implications 
For accounting service providers, as the industry is growing and developing, it is particularly important to recognize different outsourcer groups as current and potential clients, as this may lead toward more efficient marketing efforts where, instead of targeting average customers based on demographics, marketing can be more focused and targeted directly at real behavior-based target groups. This is also important with the current clients. For example, more services could be offered to Thriving outsourcers, while with Annoyed outsourcers accounting firms may need closer cooperation to understand their needs and improve trust, attitudes of management and the skills of the client in order to enhance customer satisfaction. Then there might be the small group of Convenient outsourcers, who are clients that may not need any big marketing efforts, but are contend with the current situation. However, Convenient outsourcers may respond positively to marketing related to technological benefits offered by outsourcing. From the client firm perspective, the results also indicate how important it is to consider the general approach to, existing experiences of, and future plans for accounting outsourcing in order to realize positive effects for firm performance. For small and medium-sized firms prone to outsource their accounting, the results provide different perspectives in addition to tangible cost reductions to consider in order to realize benefits from outsourcing and not only doing it out of necessity. On the other hand, the different latent classes may benefit from different kinds of outsourcing strategies (see Hanafizadeh and Zareravasan, 2020): Thriving outsourcers may rely on business process outsourcing where the service provider is responsible for performing an entire accounting function, including IT systems and their maintenance, or cloud services, as they may outsource more and more accounting transactions. Annoyed outsourcers may be more satisfied with application service providers where they only rent generally available packaged software applications and related services for conducting accounting. Convenient outsourcers may be satisfied with different strategies, e.g. cloud services, where the service provider offers a wide variety of services. 


\section{Limitations and further studies}

Although we adopted the measures from earlier research, there may always be additional influencing variables and alternative measures that are excluded from this study. Also additional control variables, like the quality of the outsourcing service, would probably increase understanding relating to this phenomenon The measurement of all variables was based on subjective perceptions, rather than objective figures. Our data was cross-sectional, which hinders us to establish causality in the same way as a longitudinal data would have allowed us to do. The generalizability of the current study may suffer due to the fact that the data is small $(\mathrm{N}=261)$ and contains respondents who are mainly from SMEs in one country only.

We highlight three avenues for further studies. First, we encourage researchers to apply novel theoretical approaches in order to better explain performance of accounting outsourcing firms. Second, different groups of accounting outsourcers need further research attention. We revealed three classes of outsourcers, but more research is needed in order to better understand different types of unobservable heterogeneity of outsourcers. Additionally, more research is needed in the context of accounting outsourcing in relation to concepts outsourcing benefits, firm capabilities, and firm performance, along with the relationships between them.

\section{References}

Abdul-Halim, H., Che-Ha, N. and Geare, A. (2009), “The influence of business strategy on the decision to outsource human resource activities: a study of Malaysian manufacturing organisations", Journal of Human Resource Costing \& Accounting, Vol. 13 No. 4, pp. 274293. 
Aman, A., Hamzah, N., Amiruddin, R. and Maelah, R. (2012), "Transaction costs in finance and accounting offshore outsourcing: a case of Malaysia”, Strategic Outsourcing: An International Journal, Vol. 5 No. 1, pp. 72-88.

Anderson, S.W., Glenn, D. and Sedatole, K.L. (2000), "Sourcing parts of complex products: evidence on transactions costs, high-powered incentives and ex-post opportunism", Accounting, Organizations and Society, Vol. 25 No. 8, pp. 723-749.

Andone, I.I. and Pavaloaia, V.-D.W. (2010), “Outsourcing the business services”, Informatica Economica, Vol. 14 No. 1, pp. 163-171.

Armstrong, J.S. and Overton, T.S. (1977), “Estimating Nonresponse Bias in Mail Surveys”, Journal of Marketing Research, Vol. 14 No. 3, pp. 396-402.

Asatiani, A., Apte, U., Penttinen, E., Rönkkö, M. and Saarinen, T., (2019), "Impact of accounting process characteristics on accounting outsourcing - Comparison of users and non-users of cloud-based accounting information systems", International Journal of Accounting Information Systems, Vol. 34, article 100419.

Barney, J. (1991), "Firm resources and sustained competitive advantage", Journal of Management, Vol. 17 No. 1, pp. 99-120.

Barney, J.B. and Hesterly, W.S. (2012), Strategic management and competitive advantage: Concepts and cases (4th ed.),Pearson, New Jersey.

Bart, Y., Shankar, V., Sultan, F. and Urban, G.L. (2005), “Are the drivers and role of online trust the same for all web sites and consumers? A large-scale exploratory empirical study", Journal of Marketing, Vol. 69 No. 4, pp. 133-152.

Becker, J.M., Rai, A., Ringle, C.M. and Völckner, F. (2013). ’Discovering unobserved heterogeneity in structural equation models to avert validity threats", MIS quarterly, Vol. 37 No. 3, pp. 665-694. 
Bowen, R.M., Rajgopal, S. and Venkatachalam, M. (2008), ”Accounting discretion, corporate governance, and firm performance", Contemporary Accounting Research, Vol. 25 No. 2, pp. $351-405$.

Browne, M.W. and Cudeck, R. (1993), “Alternative ways of assessing model fit”, Bollen, K. and Long; J.S. (Eds.), Testing Structural Equation Models. Sage Publications Inc., Palm Spring. Bustinza, O.F., Arias-Aranda, D. and Gutierrez-Gutierrez, L. (2010), “Outsourcing, competitive capabilities and performance: an empirical study in service firms", International Journal of Production Economics, Vol. 126 No. 2, pp. 276-288.

Coase, R.H. (1937), “The nature of firm”, Economica, Vol. 4 No. 16, pp. 386-405. Reprinted in: Coase, R.H. (1988), The firm the market and the law. The University of Chigago Press, Chicago and London.

Carey, P., Subramaniam, N. and Ching, K.C.W. (2006), "Internal audit outsourcing in Australia", Accounting \& Finance, Vol. 46 No. 1, pp. 11-30.

Dibbern, J. and Heinzl, A. (2002), “Outsourcing of information systems in small and medium sized enterprises: a test of a multi-theoretical causal model", In: Outsourcing of information systems in small and medium sized enterprises: a test of a multi-theoretical causal model. Information Systems Outsourcing, Springer, pp. 77-99.

Eldenburg, L.G., Price III, R.A. and Román, F.J. (2019), “An exploratory study of factors affecting the longevity of manufacturing operations offshore", Accounting, Organizations and Society, Vol. 75, pp. 59-78.

Ellinger, A.E., Daugherty, P.J. and Keller, S. (2000), “The relationship between marketing/logistics interdepartmental integration and performance in US manufacturing firms: An empirical study", Journal of Business Logistics, Vol. 21 No. 1, p. 1.

Everaert, P., Sarens, G. and Rommel, J. (2010), "Using Transaction Cost Economics to explain outsourcing of accounting”, Small Business Economics, Vol. 35 No. 1, pp. 93-112. 
Gilley, K.M., Greer, C.R. and Rasheed, A.A. (2004), "Human resource outsourcing and organizational performance in manufacturing firms", Journal of Business Research, Vol. 57 No. 3, p. 232.

Giustiniano, L. and Clarioni, G. (2013), “The impact of outsourcing on business performance: An empirical analysis", Journal of Modern Accounting and Auditing, Vol. 9 No 2, p. 153.

Grafton, J., Lillis, A.M. and Widener, S.K. (2010), "The role of performance measurement and evaluation in building organizational capabilities and performance", Accounting, Organizations and Society, Vol. 35 No. 7, pp. 689-706.

Golhar, D.Y. and Deshpande, S.P.(2009), “Outsourcing for financial success? An exploratory study", Advances in Competitiveness Research, Vol. 17 No. 1, pp. 41-51.

Grant, R.M. (1991), “The resource-based theory of competitive advantage: implications for strategy formulation”, California Management Review, Vol. 33 No. 3, pp. 114-135.

Görg, H. and Hanley, A. (2004), "Does outsourcing increase profitability”, The Economic and Social Review, Vol. 35 No. 3, pp. 267-288.

Haapanen, L., Juntunen, M. and Juntunen, J. (2016), 'Firms' capability portfolios throughout international expansion. A latent class approach", Journal of Business Research, Vol. 69 No. 12, pp. 5578-5586.

Hair, J.F., Black, W.C., Babin, B.J. and Anderson, R.E. (2009). Multivariate Data Analysis. Pearson Education Inc., New Jersey.

Hanafizadeh, P., \& Ravasan, A. Z. (2017), “An investigation into the factors influencing the outsourcing decision of e-banking services: A multi-perspective framework", Journal of Global Operations and Strategic Sourcing, Vol. 10 No. 1, pp. 67-89.

Hanafizadeh, P., \& Zareravasan, A. (2020), “A Systematic Literature Review on IT Outsourcing Decision and Future Research Directions", Journal of Global Information Management, Vol. 28 No. 2, pp. 160-201. 
Henri, J. (2006), “Management control systems and strategy: A resource-based perspective”, Accounting, Organizations and Society, Vol. 31 No. 6, pp. 529-558.

Hu, L. and Bentler, P. M. (1999), "Cutoff criteria for fit indexes in covariance structure analysis: Conventional criteria versus new alternatives”, Structural Equation Modeling: A Multidisciplinary Journal, Vol. 6 No. 1, pp. 1-55.

Jaccard, J. and Wan, C.K. (1996), Lisrel Approaches to Interaction Effect in Multiple Regression. Sage Publications Inc., California.

Jedidi, K., Jagpal, H.S. and DeSarbo, W.S. (1997), "Finite-mixture structural equation models for response-based segmentation and unobserved heterogeneity", Marketing Science, Vol. 16 No. 1, pp. 39-59.

Juntunen, J. (2010), "Functional spin-offs in logisics service markets", International Journal of Logistics: Research and Applications, Vol. 13 No. 2, pp. 121-132.

Juntunen, J., Grant, D.B. and Juga, J. (2010), ”Short-run vs long-run trade-offs in outsourcing relationships", Strategic Outsourcing: An International Journal, Vol. 3 No. 3, pp. 211-225. Juntunen, J., Juntunen, M. and Juga, J. (2015), ”Latent classes of service quality, logistics costs and loyalty", International Journal of Logistics Research and Applications, Vo. 18 No. 5, pp. $442-458$.

Kremic, T., Icmeli Tukel, O. and Rom, W.O. (2006), “Outsourcing decision support: a survey of benefits, risks, and decision factors", Supply Chain Management: An International Journal, Vol. 11 No. 6, pp. 467-482.

Khurana, I.K. and Raman, K.K. (2006), ’Do investors care about the auditor's economic dependence on the client?", Contemporary Accounting Research, Vol. 23 No. 4, pp. 977-1016. Lambert, D.M. and Harrington, T.C. (1990), "Measuring nonresponse bias in customer service mail surveys", Journal of Business Logistics, Vol. 11 No. 2, pp. 5-20. 
Lepistö, S., Dobroszek, J., Lepistö, L. and Zarzycka, E. (2020), “Controlling outsourced management accounting to build legitimacy”, Qualitative Research in Accounting \& Management, Vol. 17 No. 3, pp. 435-463.

MacCallum, R.C., Browne, M.W. and Sugawara, H.M. (1996), "Power analysis and determination of sample size for covariance structure modeling”, Psychological Methods, Vol. 1 No. 2, pp. 130-149.

Maelah, R., Aman, A., Hamzah, N. and Amiruddin, R. (2010), ”Accounting outsourcing turnback: process and issues", Strategic Outsourcing: An International Journal, Vol. 3 No. 3, pp. 226245.

Marriott, N. and Marriott, P. (2000), "Professional accountants and the development of a management accounting service for the small firm: barriers and possibilities", Management Accounting Research, Vol. 11 No. 4, pp. 475-492.

McLachlan, G. and Peel, D. (2000), Finite mixture models. John Wiley and Sons, New York. Michael, A. (2008). “Outsourcing the finance function”, Financial Management, (April), 32-34.

Ministy of Economic Affairs and Employment (2019), "Sector report for the financial administration sector 2019”, Publications of the Ministry of Economic Affairs and Employment Sector reports 2019:50. http://urn.fi/URN:ISBN:978-952-327-453-2

Mitter, C. and Hiebl, M.R. (2017), “The role of management accounting in international entrepreneurship”, Journal of Accounting \& Organizational Change, Vol. 13 No. 3, pp. 381409.

Mouritsen, J., Hansen, A. and Hansen, C.Ø. (2001), “Inter-organizational controls and organizational competencies: episodes around target cost management/functional analysis and open book accounting”, Management Accounting Research, Vol. 12 No. 2, pp. 221-244. 
Munjal, S., Requejo, I. and Kundu, S.K. (2019), “Offshore outsourcing and firm performance: Moderating effects of size, growth and slack resources", Journal of Business Research, Vol. 103 (October), pp. 484-494.

Murphy, P.J., Wu, Z., Welsch, H., Heiser, D.R., Young, S.T. and Jiang, B. (2012), ’Small firm entrepreneurial outsourcing: traditional problems, nontraditional solutions", Strategic Outsourcing: An International Journal, Vol. 5 No. 3, pp. 248-275.

Muthén, L.K. and Muthén, B.O. (2017), Mplus User's Guide. Statistical Analysis With Latent Variables. Eighth Edition, Los Angeles, CA.

Nadeem, W., Juntunen, M. and Juntunen, J. (2017), “Consumer segments in social commerce: A latent class approach”, Journal of Consumer Behaviour, Vol. 16 No. 3, pp. 279-292.

Nicholson, B. and Aman, A. (2012), ”Managing attrition in offshore finance and accounting outsourcing: Exploring the interplay of competing institutional logics", Strategic Outsourcing: An International Journal, Vol. 5 No. 3, pp. 232-247.

Nicholson, B., Jones, J. and Espenlaub, S. (2006), “Transaction costs and control of outsourced accounting: Case evidence from India”, Management Accounting Research, Vol. 17 No. 3, pp. $238-258$.

Nordin, F. (2008), “Linkages between service sourcing decisions and competitive advantage: A review, propositions, and illustrating cases", International Journal of Production Economics, Vol. 114 No. 1, pp. 40-55.

Pinjala, S.K., Pintelon, L. and Vereecke, A. (2006), “An empirical investigation on the relationship between business and maintenance strategies", International Journal of Production Economics, Vol. 104 No. 1, pp. 214-229.

Prahalad, C.K. and Hamel, G. (1990), “The core competence of the corporation”, Harvard Business Review, Vol. 68 No. 3, pp. 79-91. 
Smith, J.A., Morris, J. and Ezzamel, M. (2005), "Organisational change, outsourcing and the impact on management accounting", The British Accounting Review, Vol. 37 No. 4, pp. 415-441.

Speklé, R.F. (2001), “Explaining management control structure variety: a transaction cost economics perspective", Accounting, Organizations and Society, Vol. 26 No. 4, pp. 419-441.

Speklé, R.F., Van Elten, H.J. and Kruis, A. (2007), “Sourcing of internal auditing: An empirical study", Management Accounting Research, Vol. 18 No. 1, pp. 102-124.

Steenkamp JB, van Trijp H. (1991) The use of lisrel in validating marketing constructs. International Journal of Research in Marketing, Vol. 8 No. 4, pp. 283-299.

Taloushallintoliitto ry (2021) [The Association of Finnish Accounting Firms]. https://taloushallintoliitto.fi/tietoa-meista/tutkimuksia-ja-tietoa-alasta/tilitoimistoala-suomessa. Accessed June 11, 2021.

Teece, D.J., Pisano, G. and Shuen, A. (1997), "Dynamic capabilities and strategic management”, Strategic Management Journal, Vol. 18 No. 7, pp. 509-533.

Tolvanen, A. (2007), Latent growth mixture modeling: a simulation study. Jyväskylä University Press, Jyväskylä.

Van der Meer-Kooistra, J. and Vosselman, E.G. (2000), "Management control of interfirm transactional relationships: the case of industrial renovation and maintenance", Accounting, Organizations and Society, Vol. 25 No. 1, pp. 51-77.

Venkatesan, R. (1992), "Strategic sourcing: to make or not to make", Harvard Business Review, November-December.

Vogel, V., Evanschitzky, H. and Ramaseshan, B. (2008), “Customer Equity Drivers and Future Sales”, Journal of Marketing, Vol. 72 (November), pp. 98-108.

Vosselman, E.G. (2002), “Towards horizontal archetypes of management control: a transaction cost economics perspective", Management Accounting Research, Vol. 13 No. 1, pp. 131-148. 
Wernerfelt, B. (1984), “A resource-based view of the firm”, Strategic Management Journal, Vol. 5 No. 2, pp. 171-180.

Widener, S.K. (2006), “Associations between strategic resource importance and performance measure use: The impact on firm performance", Management Accounting Research, Vol. 17 No. 4, pp. 433-457.

Widener, S.K. and Selto, F.H. (1999), "Management control systems and boundaries of the firm: why do firms outsource internal auditing activities?", Journal of Management Accounting Research, Vol. 11, pp. 45-73. 
Figure 1: The conceptual model

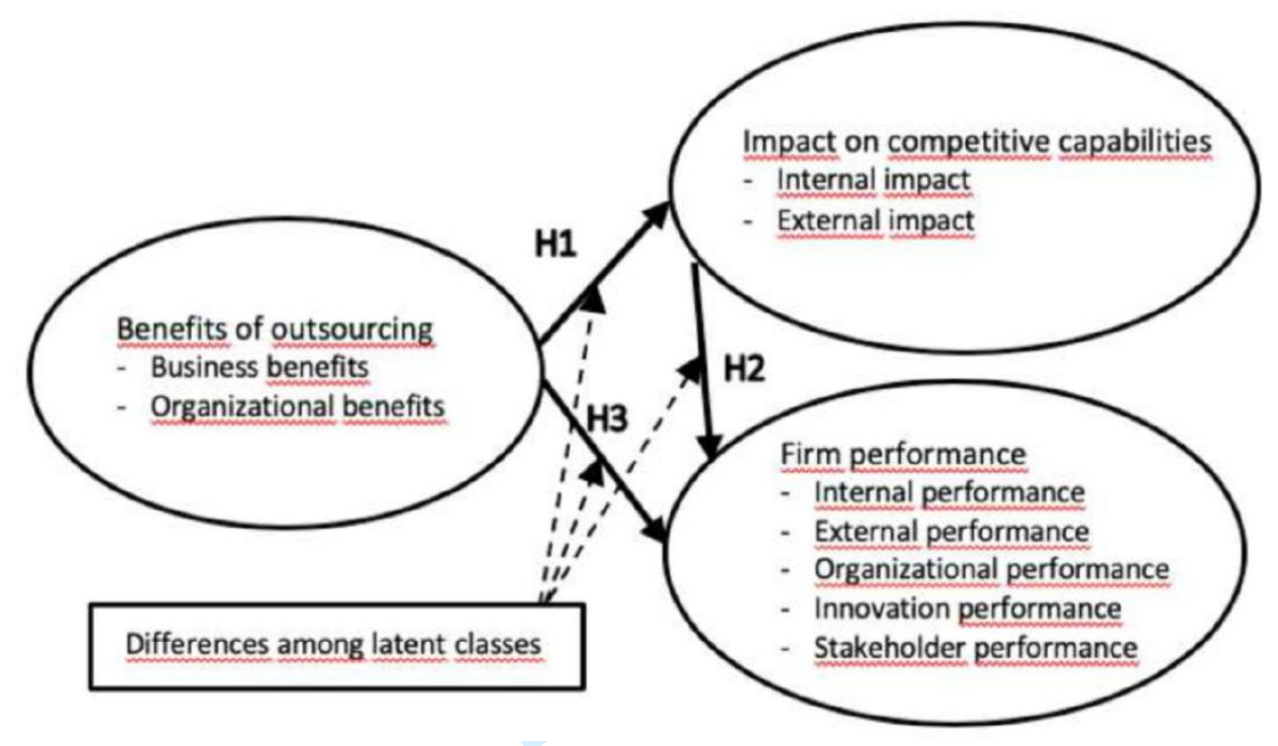
0

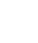

(2)

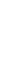

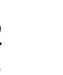

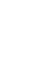

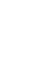

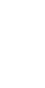

- Business benefits 
Figure 2: Kruskal-Wallis test's post hoc pairwise comparison test's mean ranks by classes

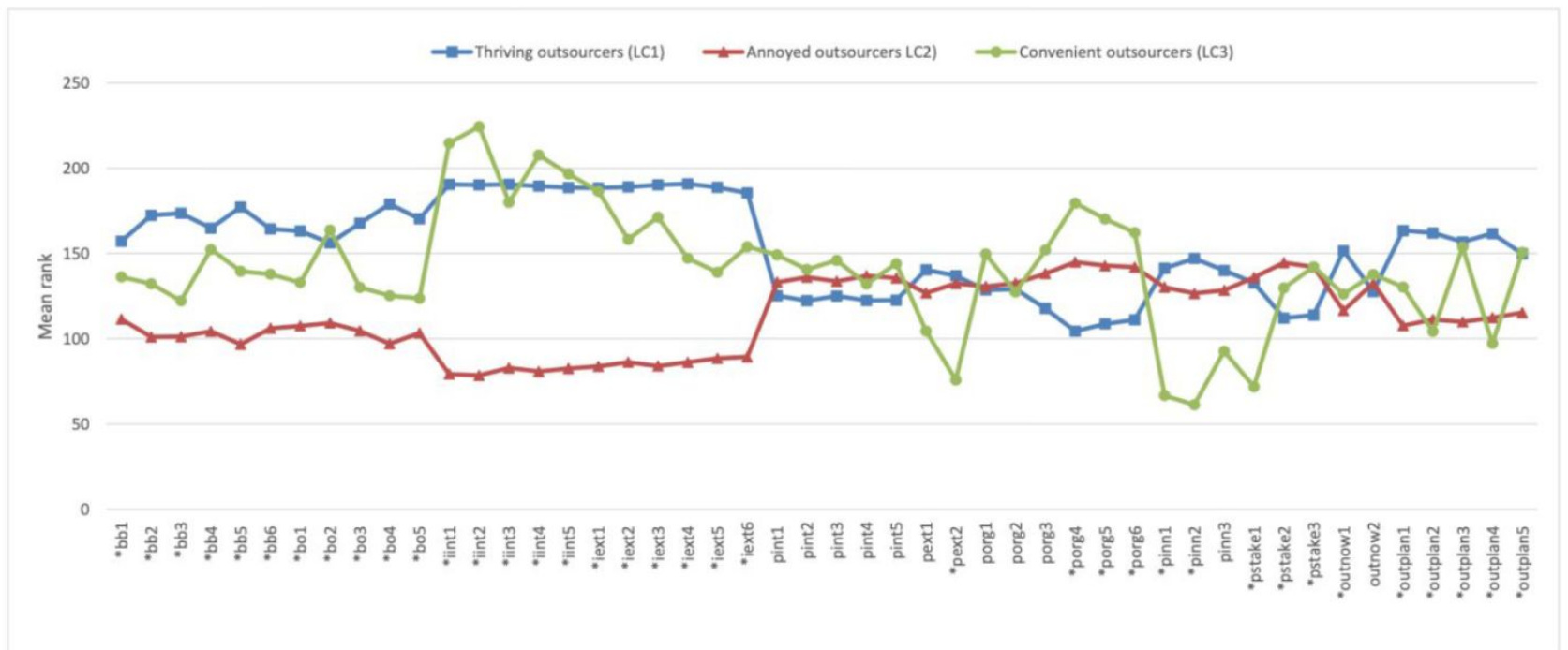

*See Kruskal-Wallis test values and pairwise comparisons test values for statistically significant differences in the mean ranks of classes in variable in Appendix 3. 
Table 1: Fit indices of the model with different numbers of latent classes

\begin{tabular}{cccccccccc}
\hline Classes & N/Class & Entropy & LogLH & AIC & BIC & ABIC & VLMRLRT & LMRALRT & PBLR \\
\hline 1 & 261 & $\mathrm{n} / \mathrm{a}$ & 15763 & 31796 & 32277 & 31949 & $\mathrm{n} / \mathrm{a}$ & $\mathrm{n} / \mathrm{a}$ & $\mathrm{n} / \mathrm{a}$ \\
2 & $115 / 146$ & 0.829 & 15686 & 31674 & 32212 & 31733 & 0.574 & 0.577 & 0.000 \\
3 & $103 / 15 / 143$ & 0.904 & 15624 & 31583 & 32178 & 31648 & 0.324 & 0.327 & 0.000 \\
4 & $15 / 9 / 131 / 106$ & 0.921 & 15584 & 31534 & 32186 & 31605 & 0.240 & 0.240 & 0.000 \\
\hline
\end{tabular}


Table 2: Average posteriori probabilities

\begin{tabular}{lccc}
\hline Class & $\begin{array}{c}\text { Thriving } \\
\text { outsourcers } \\
\text { (LC2) }\end{array}$ & $\begin{array}{c}\text { Annoyed } \\
\text { outsourcers } \\
\text { (LC1) }\end{array}$ & $\begin{array}{c}\text { Convenient } \\
\text { outsourcers } \\
\text { (LC3) }\end{array}$ \\
\hline Thriving outsourcers (LC2) & 0.943 & 0.042 & 0.016 \\
Annoyed outsourcers (LC1) & 0.019 & 0.980 & 0.001 \\
Convenient outsourcers (LC3) & 0.077 & 0.009 & 0.914 \\
\hline
\end{tabular}


Table 3: Structural models of the three latent classes

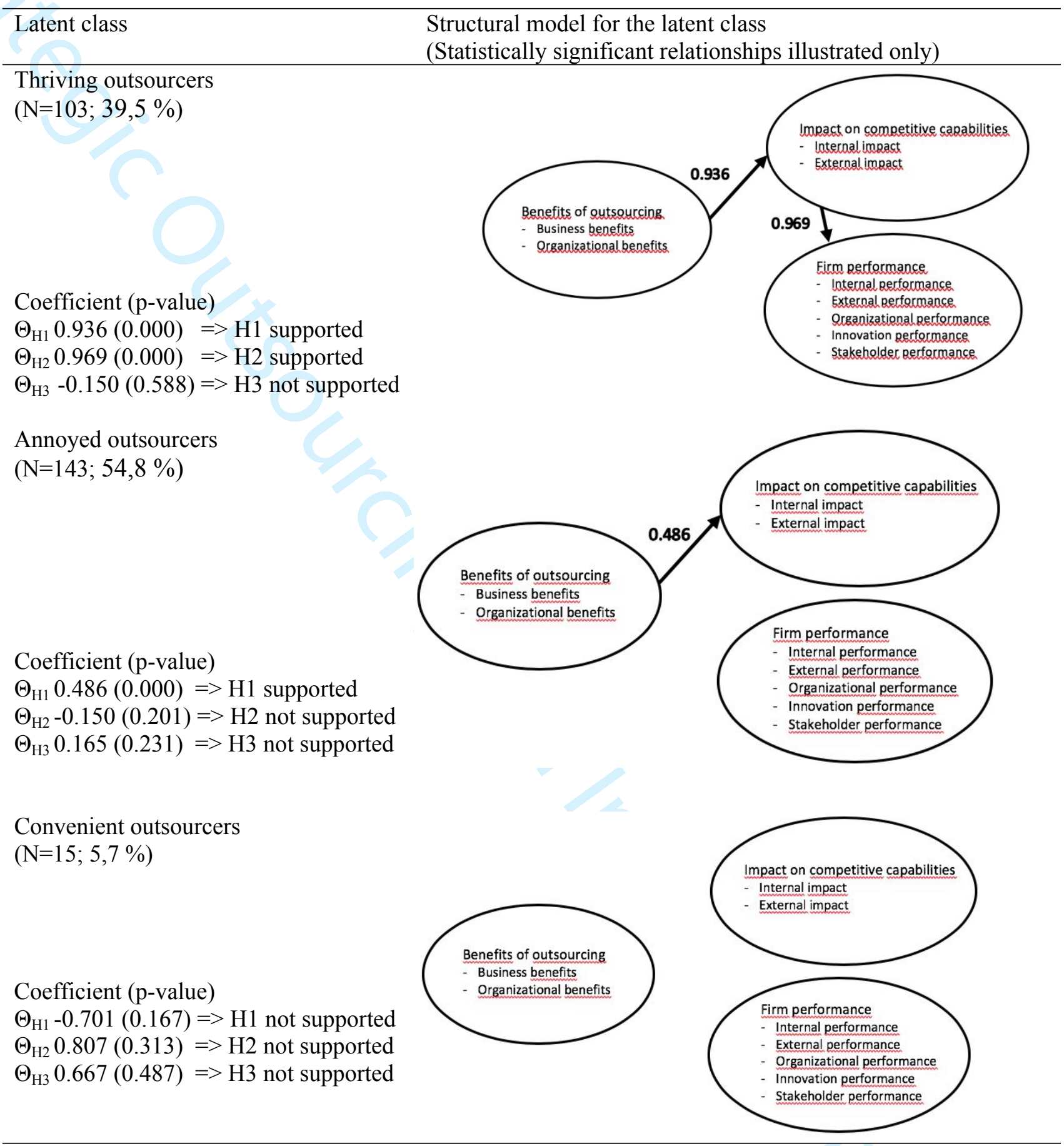


Table 4: Accounting research on outsourcing related to the findings

\begin{tabular}{|c|c|c|}
\hline Stream of accounting literature & References & Implication of the findings \\
\hline $\begin{array}{l}\text { Benefits of outsourcing } \\
\text { accounting originate from the } \\
\text { reduction of transaction costs } \\
\text { (TCE-based research), } \\
\text { suggesting a direct link } \\
\text { between firm performance and } \\
\text { outsourcing }\end{array}$ & $\begin{array}{l}\text { Smith et al. (2005), Aman et al. } \\
\text { (2012), Nicholson and Aman } \\
(2012)\end{array}$ & $\begin{array}{l}\text { No direct link is found between } \\
\text { outsourcing and firm performance } \\
\text { within any latent class of } \\
\text { accounting outsourcers }\end{array}$ \\
\hline $\begin{array}{l}\text { Outsourcing non-core } \\
\text { functions provides resources } \\
\text { for more value-adding } \\
\text { activities }\end{array}$ & $\begin{array}{l}\text { Widener and Selto (1999), } \\
\text { Mouritsen et al. (2001), Spekle } \\
\text { (2001), Smith et al. (2005), } \\
\text { Carey et al. (2006), Eldenburg } \\
\text { et al. (2019) }\end{array}$ & $\begin{array}{l}\text { Our results reveal differences } \\
\text { between outsourcers. Not all } \\
\text { accounting outsourcers deem } \\
\text { outsourcing providing more } \\
\text { resources for other activities. More } \\
\text { specifically, Thriving outsourcers } \\
\text { see the positive link between } \\
\text { outsourcing and competitive } \\
\text { capabilities, while Annoyed } \\
\text { outsourcers see the link as a } \\
\text { negative one. Convenient } \\
\text { outsourcers are content with the } \\
\text { situation in any case. }\end{array}$ \\
\hline $\begin{array}{l}\text { Firm governance/control, } \\
\text { meaning the right combination } \\
\text { of insourced and outsourced } \\
\text { activities support capabilities } \\
\text { of the firm }\end{array}$ & $\begin{array}{l}\text { Henri 2006), Widener (2006), } \\
\text { Mitter and Hiebl (2017), } \\
\text { Grafton et al. (2010) }\end{array}$ & $\begin{array}{l}\text { The latent classes of Thriving and } \\
\text { Annoyed outsourcers are in line } \\
\text { with this. While Thriving } \\
\text { outsourcers have found the right } \\
\text { combination, for Annoyed } \\
\text { outsourcers outsourcing decisions } \\
\text { does not seem to be the right } \\
\text { decision to support other } \\
\text { capabilities. }\end{array}$ \\
\hline
\end{tabular}


Appendix 1: Latent variables, their measures, factor loadings, residual variances, and fit indices.

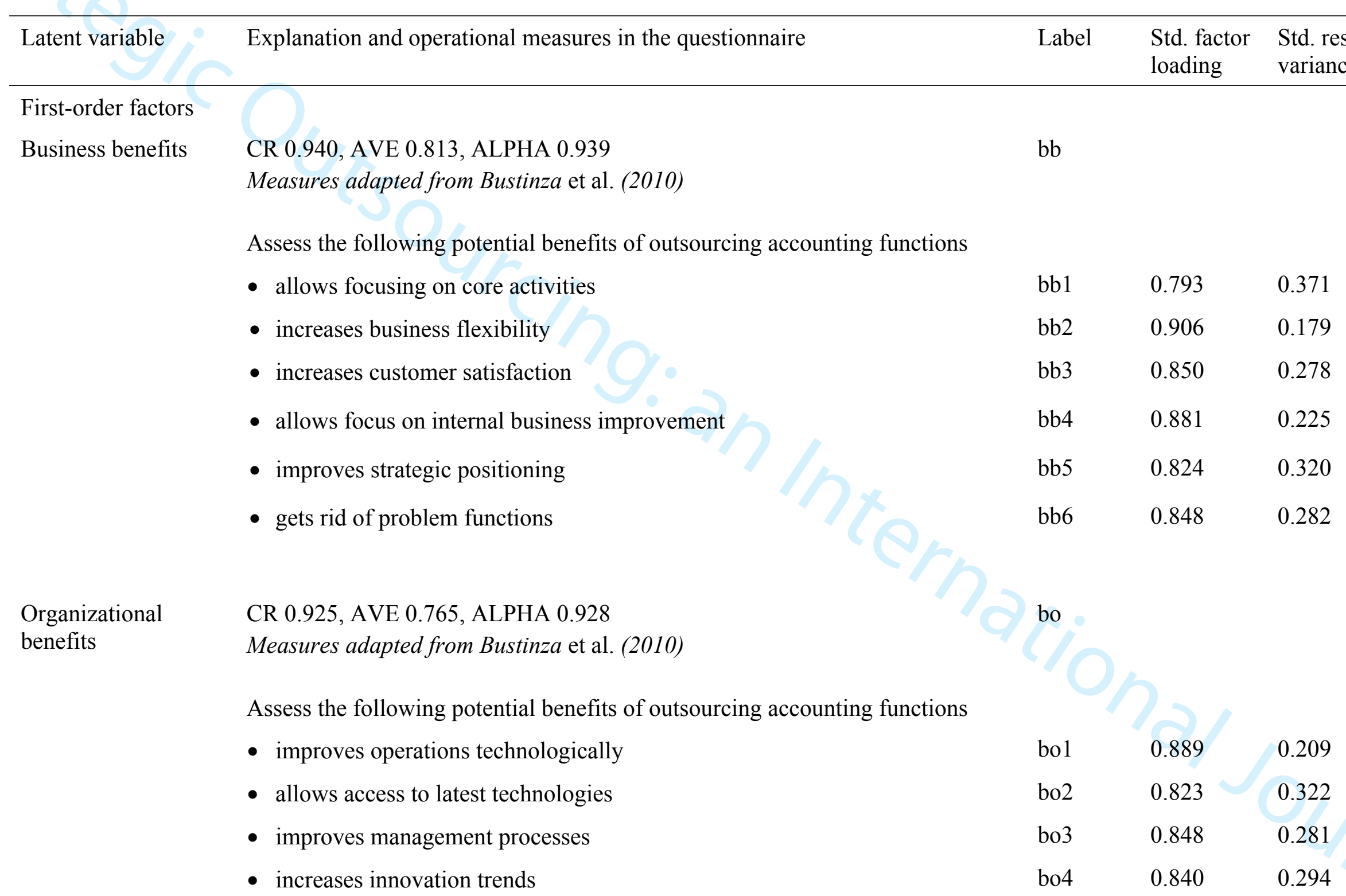


- reduces organizational risks

Internal impact

External impact capabilities of your firm

- enable punctual delivery

- enable faster delivery
CR 0.963, AVE 0.793, ALPHA 0.966

Measures adapted from Bustinza et al. (2010)

Assess the importance of an outsourcing decision on the following competitive

- increase the competitiveness of our prices

- enable us to offer consistent quality

- enable us to obtain better results from services or products

\section{CR 0.974, AVE 0.838, ALPHA 0.973}

Measures adapted from Bustinza et al. (2010)

Assess the importance of an outsourcing decision on the following competitive capabilities of your firm

- provide flexibility to face market demand

- introduce new services and products into the market more rapidly

- distribute our services or products more widely

- Increase the number of our services or products

- contribute to promoting our services and products more efficiently

- develop post-sales services and products bo5

0.848

0.280

iint

$\begin{array}{lll}\text { iint1 } & 0.926 & 0.142 \\ \text { iint2 } & 0.936 & 0.124 \\ \text { iint3 } & 0.905 & 0.181 \\ \text { iint4 } & 0.936 & 0.124 \\ \text { iint5 } & 0.919 & 0.156\end{array}$

iext

$\begin{array}{lll}\text { iext1 } & 0.905 & 0.181 \\ \text { iext2 } & 0.925 & 0.144 \\ \text { iext3 } & 0.943 & 0.111 \\ \text { iext4 } & 0.944 & 0.109 \\ \text { iext5 } & 0.937 & 0.121 \\ \text { iext6 } & 0.918 & 0.157\end{array}$


Internal business performance

External business performance

Organizational performance

\section{CR 0.912, AVE 0.772, ALPHA 0.909}

Measures adapted from Bustinza et al. (2010), Gilley et al. (2004) and Golhar and Deshpande (2009)

Please rate your firm's performance relative to similar firms in your industry over the past 12 months.

- return on assets

- return on equity

- return on investment

- return on sales

- overall financial performance

\section{CR 0.726, AVE 0.534, ALPHA 0.716}

Measures adapted from Bustinza et al. (2010), Kamyabi and Devi (2011) and Golhar and Deshpande (2009)

Please rate your firm's performance relative to similar firms in your industry over the past 12 months.

- market share on main markets

- growth in sales in main services and markets

CR 0.814, AVE 0.737, ALPHA 0.799

Measures adapted from Bustinza et al. (2010), Ellinger et al. (2000) and Gilley et al. (2004) pint

$\begin{array}{lll}\text { pint1 } & 0.926 & 0.143 \\ \text { pint2 } & 0.937 & 0.122 \\ \text { pint3 } & 0.850 & 0.278 \\ \text { pint4 } & 0.698 & 0.513 \\ \text { pint5 } & 0.664 & 0.553\end{array}$

pext

$\begin{array}{lll}\text { pext1 } & 0.663 & 0.561 \\ \text { pext2 } & 0.841 & 0.292 \\ & & \\ \text { porg } & & \\ & & \end{array}$


Please rate your firm's performance relative to similar firms in your industry over the past 12 months

- number of customer complaints

- number of services or products initiated but not finalized

porg1 0.277

- lead-time

- general level of customer satisfaction

porg2

0.244

0.941

porg3 $\quad 0.586$

0.656

- degree of loyalty of customers

porg4

0.841

0.292

- customer relations in general

porg5 0.881

porg6

0.914

0.165

Innovation performance

Stakeholder performance

\section{CR 0.883, AVE 0.682, ALPHA 0.881}

Measures adapted from Gilley et al. (2004), Görg and Hanley (2011) and Kamyabi and Devi (2011)

Please rate your firm's performance relative to similar firms in your industry over the past 12 months

- R\&D outlays

- amount of process innovations

- amount of product innovations

CR 0.741, AVE 0.595, ALPHA 0.740

Measures adapted from Gilley et al. (2004) and Giustiniano and Clarioni (2013)

Please rate your firm's performance relative to similar firms in your industry over the past 12 months

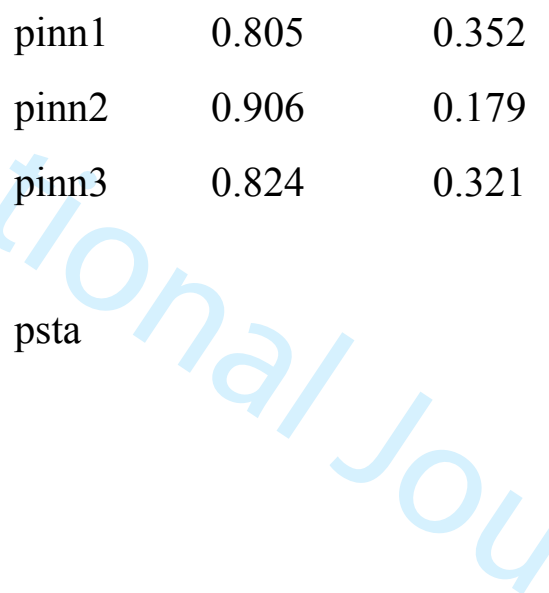


- Employment growth

- Employee morale

- Level of satisfaction with supplier relationships

Second-order factors

Benefits of

outsourcing

CR 0.968, AVE 0.652, ALPHA N/A

- business benefits

- organizational benefits

CR 0.961, AVE 0.649, ALPHA N/A

Impact of the competitive

capabilities

- internal impact

- external impact

Firm performance
CR 0.869, AVE 0.743, ALPHA N/A

- internal business performance

- external business performance

- organizational performance

- innovation performance

- stakeholder performance

$\begin{array}{lll}\text { psta1 } & 0.711 & 0.495 \\ \text { psta2 } & 0.643 & 0.587 \\ \text { psta3 } & 0.741 & 0.451\end{array}$

benefits

$\begin{array}{lll}\text { bb } & 0.949 & 0.100 \\ \text { ob } & 0.988 & 0.024\end{array}$

impact

iint $\quad 0.978 \quad 0.043$

iext $\quad 0.944 \quad 0.108$

perform

pint $\quad 0.730 \quad 0.467$

$\begin{array}{lll}\text { pext } & 0.825 & 0.319\end{array}$

porg $\quad 0.645 \quad 0.584$

$\begin{array}{lll}\text { pinn } & 0.585 & 0.658\end{array}$

$\begin{array}{lll}\text { psta } & 0.956 \quad 0.087\end{array}$ 
Control variables

Current outsourcing

- Estimate the amount of your current outsourcing of accounting functions

- Estimate the amount of accounting functions you could conduct internally

Future outsourcing plans / Outsourcing strategy

\section{CR 0.787, AVE 0.692, ALPHA 0.790}

Measures adapted from Vogel et al. (2008) and Juntunen (2010)

- We will outsource more account services to our current service provider

- We will outsource more account services to new service provider

- We will strengthen cooperation with our current service provider

- We will increase competition among our service providers

- We will recommend our current service provider to our partners outnow1

outnow2

outplan1

outplan2

outplan3

outplan4

outplan5 
Appendix 2: The structural equation model

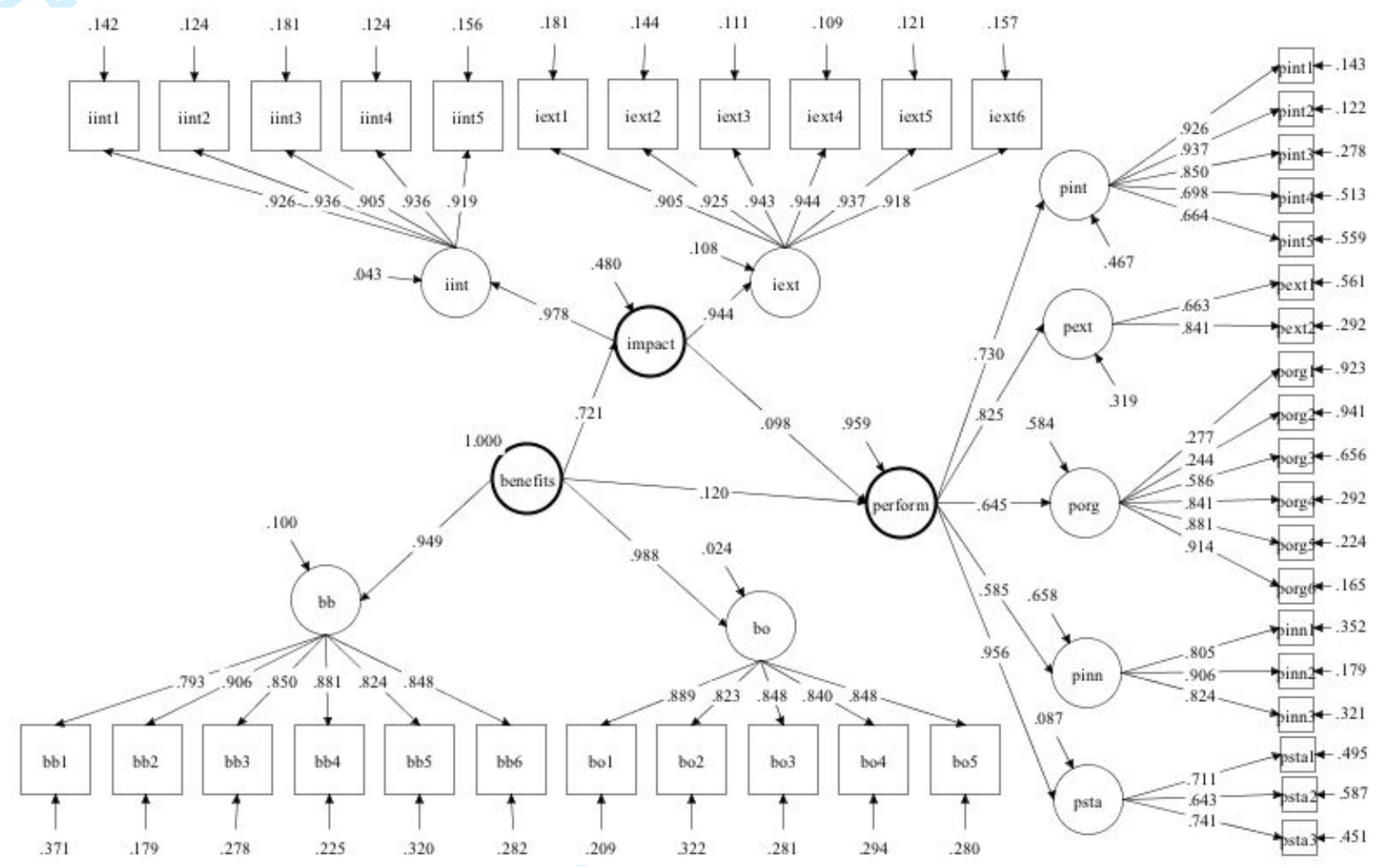


Appendix 3: Kruskal-Wallis test values and pairwise comparisons test values

\begin{tabular}{|c|c|c|c|c|}
\hline Factor & Label & H-value & $p$-value & Pairwise comparisons \\
\hline \multirow[t]{6}{*}{ Business benefits } & bb1 & $\mathrm{H}=23.619$ & 0.000 & LCI-LC2 $p=0.000$ \\
\hline & $\mathrm{bb} 2$ & $\mathrm{H}=54.985$ & 0.000 & LCI-LC2 $\mathrm{p}=0.000$ \\
\hline & bb3 & $\mathrm{H}=57.239$ & 0.000 & LCI-LC2 $p=0.000 ;$ LC1-LC $3 p=0.037$ \\
\hline & bb4 & $\mathrm{H}=40.889$ & 0.000 & LCI-LC $2 \mathrm{p}=0.000$ \\
\hline & bb5 & $\mathrm{H}=70.916$ & 0.000 & LCI-LC2 $p=0.000$ \\
\hline & bb6 & $\mathrm{H}=36.745$ & 0.000 & LCI-LC2 $p=0.000$ \\
\hline \multirow{5}{*}{$\begin{array}{l}\text { Organizational } \\
\text { benefits }\end{array}$} & bo1 & $\mathrm{H}=33.458$ & 0.000 & LCI-LC2 $p=0.000$ \\
\hline & bo2 & $\mathrm{H}=26.815$ & 0.000 & LCI-LC $2 p=0.000 ;$ LC2-LC $3 p=0.021$ \\
\hline & bo3 & $\mathrm{H}=43.237$ & 0.000 & LCI-LC2 $\mathrm{p}=0.000$ \\
\hline & bo4 & $\mathrm{H}=73.440$ & 0.000 & LCI-LC2 $p=0.000 ;$ LC1-LC $3 p=0.026$ \\
\hline & bo5 & $\mathrm{H}=48.504$ & 0.000 & LCI-LC $2 \mathrm{p}=0.000$ \\
\hline \multirow[t]{5}{*}{ Internal impact } & iint1 & $\mathrm{H}=160.681$ & 0.000 & LCI-LC2 $p=0.000 ;$ LC2-LC3 $p=0.000$ \\
\hline & iint2 & $\mathrm{H}=167.229$ & 0.000 & LCI-LC2 $p=0.000 ;$ LC2-LC $3 p=0.000$ \\
\hline & iint3 & $\mathrm{H}=137.471$ & 0.000 & LCI-LC2 $p=0.000 ;$ LC2-LC $3 p=0.000$ \\
\hline & iint4 & $\mathrm{H}=149.669$ & 0.000 & LCI-LC2 $p=0.000 ;$ LC2-LC $3 p=0.000$ \\
\hline & iint5 & $\mathrm{H}=138.104$ & 0.000 & LCI-LC2 $\mathrm{p}=0.000 ;$ LC2-LC $3 \mathrm{p}=0.000$ \\
\hline \multirow[t]{6}{*}{ External impact } & iext1 & $\mathrm{H}=130.308$ & 0.000 & LCI-LC2 $p=0.000 ;$ LC2-LC3 $p=0.000$ \\
\hline & iext2 & $\mathrm{H}=121.322$ & 0.000 & LCI-LC2 $p=0.000 ;$ LC2-LC $3 p=0.001$ \\
\hline & iext3 & $\mathrm{H}=135.505$ & 0.000 & LCI-LC2 $p=0.000 ;$ LC2-LC $3 p=0.000$ \\
\hline & iext4 & $\mathrm{H}=126.549$ & 0.000 & LCI-LC2 $p=0.000 ;$ LC2-LC3 $p=0.005$ \\
\hline & iext5 & $\mathrm{H}=117.336$ & 0.000 & LCI-LC2 $p=0.000 ;$ LC2-LC3 $p=0.028$ \\
\hline & iext6 & $\mathrm{H}=107.767$ & 0.000 & $2 \mathrm{p}=0.000 ; \mathrm{LC} 2-\mathrm{LC} 3 \mathrm{p}=0.003$ \\
\hline \multirow{5}{*}{$\begin{array}{l}\text { Internal business } \\
\text { performance }\end{array}$} & pint1 & $\mathrm{H}=1.736$ & 0.420 & \\
\hline & pint2 & $\mathrm{H}=2.425$ & 0.297 & \\
\hline & pint3 & $\mathrm{H}=1.489$ & 0.475 & \\
\hline & pint4 & $\mathrm{H}=2.341$ & 0.310 & \\
\hline & pint5 & $\mathrm{H}=2.390$ & 0.303 & \\
\hline \multirow{2}{*}{$\begin{array}{l}\text { External business } \\
\text { performance }\end{array}$} & pext1 & $\mathrm{H}=4.104$ & 0.128 & \\
\hline & pext2 & $\mathrm{H}=9.262$ & 0.010 & LC1-LC3 $p=0.007 ;$ LC2-LC3 $p=0.013$ \\
\hline \multirow{6}{*}{$\begin{array}{l}\text { Organizational } \\
\text { performance }\end{array}$} & porg1 & $\mathrm{H}=1.050$ & 0.592 & \\
\hline & porg2 & $\mathrm{H}=0.162$ & 0.922 & \\
\hline & porg3 & $\mathrm{H}=5.879$ & 0.053 & \\
\hline & porg4 & $H=26.794$ & 0.000 & LC1-LC2 $p=0.000 ;$ LC1-LC3 $p=0.000$ \\
\hline & porg5 & $\mathrm{H}=18.152$ & 0.000 & LC1-LC2 $p=0.001 ; L C 1-L C 3 p=0.006$ \\
\hline & porg6 & $\mathrm{H}=13.986$ & 0.001 & LC1-LC2 $p=0.003 ; \mathrm{LC} 1-\mathrm{LC} 3 \mathrm{p}=0.030$ \\
\hline
\end{tabular}




\begin{tabular}{|c|c|c|c|c|}
\hline Innovation & pinn 1 & $\mathrm{H}=13.438$ & 0.001 & LC1-LC3 $p=0.001 ;$ LC2-LC3 $p=0.005$ \\
\hline & pinn2 & $\mathrm{H}=18.894$ & 0.000 & LC1-LC3 $p=0.000 ;$ LC2-LC3 $p=0.003$ \\
\hline & pinn3 & $\mathrm{H}=5.788$ & 0.055 & \\
\hline Stakeholder & pstake1 & $\mathrm{H}=10.536$ & 0.005 & LC1-LC3 $p=0.008 ;$ LC2-LC3 $p=0.004$ \\
\hline & pstake2 & $\mathrm{H}=11.815$ & 0.003 & LCI-LC2 $p=0.002$ \\
\hline & pstake3 & $\mathrm{H}=9.233$ & 0.010 & LCI-LC2 $p=0.009$ \\
\hline Current outsourcing & outnow1 & $\mathrm{H}=13.453$ & 0.001 & LCI-LC2 $p=0.001$ \\
\hline & outnow2 & $\mathrm{H}=0.392$ & 0.822 & \\
\hline Outsourcing plans & outplan 1 & $\mathrm{H}=36.620$ & 0.000 & LCI-LC2 $\mathrm{p}=0.000$ \\
\hline & outplan2 & $\mathrm{H}=36.358$ & 0.000 & LCI-LC2 $p=0.000 ;$ LC1-LC $3 p=0.006$ \\
\hline & outplan3 & $H=25.791$ & 0.000 & LCI-LC2 $\mathrm{p}=0.000$ \\
\hline & outplan4 & $\mathrm{H}=33.100$ & 0.000 & LCI-LC2 $p=0.000 ;$ LC1-LC3 $p=0.003$ \\
\hline & outplan 5 & $\mathrm{H}=14.175$ & 0.001 & LCI-LC2 $p=0.001$ \\
\hline
\end{tabular}

